\title{
An isoform of the plastid RNA polymerase- associated protein FSD3 negatively regulates chloroplast development
}

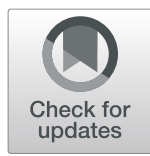

Lee Sangyool ${ }^{1}$, Joung Young Hee ${ }^{1}$, Kim Ju-Kon², Choi Yang Do ${ }^{3,4}$ and Jang Geupil ${ }^{*}$

\begin{abstract}
Background: Plastid-encoded RNA polymerase (PEP) plays an essential role in chloroplast development by governing the expression of genes involved in photosynthesis. At least 12 PEP-associated proteins (PAPs), including FSD3/PAP4, regulate PEP activity and chloroplast development by modulating formation of the PEP complex.

Results: In this study, we identified FSD3S, a splicing variant of FSD3; the FSD3 and FSD3S transcripts encode proteins with identical N-termini, but different C-termini. Characterization of FSD3 and FSD3S proteins showed that the C-terminal region of FSD3S contains a transmembrane domain, which promotes FSD3S localization to the chloroplast membrane but not to nucleoids, in contrast to FSD3, which localizes to the chloroplast nucleoid. We also found that overexpression of FSD3S negatively affects photosynthetic activity and chloroplast development by reducing expression of genes involved in photosynthesis. In addition, FSD3S failed to complement the chloroplast developmental defects in the fsd3 mutant.

Conclusion: These results suggest FSD3 and FSD3S, with their distinct localization patterns, have different functions in chloroplast development, and FSD3S negatively regulates expression of PEP-dependent chloroplast genes, and development of chloroplasts.
\end{abstract}

Keywords: Chloroplast, Plastid-encoded RNA polymerase, PEP-associated protein, FSD3, FSD3S, Alternative splicing

\section{Background}

Chloroplasts have a unique genome and two distinct RNA polymerases, the nuclear-encoded RNA polymerase (NEP) and the plastid-encoded RNA polymerase (PEP), that mediate the transcription of plastid genes. NEP is a single-subunit RNA polymerase and PEP is a multimeric RNA polymerase composed of four core proteins, rpoA, rpoB, rpoC1, and rpoC2 [1-3]. Both NEP and PEP are required for chloroplast development $[4,5]$. For example, the mutants with defects in RPOTp or RPOTmp encoding NEP show delayed chloroplast biogenesis and retarded growth, and the mutants lacking PEP activity display albino/ivory phenotypes [6-11]. It has been assumed that NEP functions at the beginning of chloroplast biogenesis and PEP functions in mature chloroplasts, based on the distinct activity between NEP

\footnotetext{
* Correspondence: yk3@jnu.ac.kr

'School of Biological Sciences and Technology, Chonnam National

University, Gwangju 61186, Republic of Korea

Full list of author information is available at the end of the article
}

and PEP; NEP is responsible for the expression of rpoB and other housekeeping genes, and PEP is responsible for the expression of photosynthesis-related genes. However, many studies using tobacco (Nicotiana tabacum) or barley (Hordeum vulgare) mutants lacking PEP activity showed that both NEP and PEP are active during all stages of chloroplast development $[4,5,7]$.

PEP activity is essential for the formation of fully active chloroplasts, as it promotes the expression of photosynthesis-related genes [3]. PEP forms a complex with PEP-associated proteins (PAPs), and the Arabidopsis thaliana nuclear genome contains at least 12 PAP genes [3, 12], and all PAPs have also been identified in the nucleoid or transcriptionally active chromosome (TAC) proteomes [1316]. Previous genetic approaches have demonstrated the essential role of PAPs in the regulation of PEP activity and chloroplast development. The expression of PEP-dependent genes is suppressed in mutant plants that do not express PAPS, resulting in defects in chloroplast development [13, 16-24]. Furthermore, studies of protein-protein interactions 
showed that each PAP interacts with other PAPs or PEP core proteins, indicating that the establishment of the PEP complex is a key mechanism controlling PEP activity and chloroplast development [3]. For example, pTAC3/PAP1 interacts with $\alpha$ core subunit of PEP [17], and pTAC14/PAP7 interacts with pTAC12/PAP5 [21]. FRUCTOKINASE-LIKE PROTEINS1 (FLN1)/PAP6 interacts with THIOREDOXIN $\mathrm{Z}$ (TrxZ)/PAP10 and FLN2 [22, 24], and FSD3/PAP4 interacts with FSD2/PAP9 [20]. pTAC7/PAP12 and pTAC10/ PAP3 showed a broad range of interactions with other PAPs $[25,26]$. A study by Pfalz et al. (2015) suggested that pTAC2/PAP2, pTAC10/PAP3, pTAC12/PAP5, and MurE/ PAP11 play a key role in promoting accumulation of the fully assembled PEP complex [27].

The Arabidopsis thaliana genome contains three genes encoding iron superoxide dismutases, FSD1, FSD2/PAP9, and FSD3/PAP4; however, several lines of evidence suggest that FSD2 and FSD3 function in chloroplast development. FSD2 and FSD3 proteins localize in the chloroplasts and FSD1 localizes in the cytoplasm [20,28]. Similar to other mutant plants in which the expression of PAPs is knocked out, $f s d 2$ and $f s d 3$ mutants show defects in chloroplast development, leading to a bleached-leaf phenotype. Unlike the $f s d 2$ and $f s d 3$ mutant plants, the $f s d 1$ mutant does not have defects in leaf color, although the expression level of FSD1 is around 50-fold higher than that of FSD3 [20, 29]. COPPER SUPEROXIDE DISMUTASE2 (CSD2) localizes in the chloroplasts and plays a key role in reactive oxygen species (ROS) scavenging in the chloroplasts [30, 31]. CSD2 expression is much higher compared to other superoxide dismutase genes (around 100-fold higher than FSD3) [29]. However, the $c s d 2$ mutant does not show the bleached-leaf phenotype as PAP mutant plants do [32, 33]. These results suggest that FSD2 and FSD3 have specialized functions in chloroplast development.

A single gene that contains introns can give rise to several different mRNAs via alternative splicing, thus contributing to the diversity of the proteome in eukaryotes, including plants [34]. In Arabidopsis and rice (Oryza sativa), only 21.7 and $19.9 \%$ of genes lack introns respectively, suggesting that alternative splicing is deeply involved in the regulation of plant development and physiology [35, 36]. Alternative splicing patterns are regulated with plant developmental stage and are frequently affected by environmental signals [37, 38]. Alternative splicing can regulate transcript abundance through RNA degradation pathways such as nonsense-mediated decay [39]. Splicing variants can encode protein isoforms with different subcellular localizations and functions, due to the insertion or deletion of functional units such as signal peptides and transmembrane (TM) domains [40, 41].

During senescence in plants, mature chloroplasts transform into gerontoplasts and photosynthetic performance decreases. PAPs play essential roles in controlling the activity of PEP, which is responsible for chloroplast development and photosynthetic activity. To understand the functions of PAPs in this process, we attempted to clone PAPS and identified FSD3S, a splicing variant of FSD3/ PAP4 that includes two unspliced introns. Unlike FSD3 proteins, which localize to the chloroplast nucleoids, FSD3S proteins have a TM domain in the C-terminal region and tended to localize to chloroplast membranes. To understand the function of FSD3S in chloroplast development, we examined the effect of FSD3S overexpression. Overexpression of FSD3S did not complement the chloroplast developmental defects in the $f s d 3$ mutants. In addition, the overexpression of FSD $3 S$ negatively regulated photosynthetic activity and chloroplast development by reducing expression of PEP-dependent genes. These results suggest FSD3 and FSD3S have different functions in chloroplast development, and FSD3S is involved in the negative regulation of PEP activity and chloroplast development.

\section{Results}

FSD3S, a splicing variant of FSD3

PAPs regulate chloroplast development by controlling activity of the PEP complex. We identified FSD3S, a splicing variant of FSD3/PAP4. FSD3 contains 8 exons and the mature FSD 3 mRNA is generated by the removal of 7 introns from the pre-mRNA by splicing. By contrast, FSD $3 S$ contains only 6 exons; the 6th and 7th introns remain in the mRNA (Fig. 1a). Comparison of the predicted amino acid sequences of FSD3 and FSD3S showed that the C-terminal region of FSD3S between amino acids 215-256 was composed of different amino acids from those of FSD3 due to the presence of the 6th and 7th introns (Additional file 1: Figure S1). The stop codon of FSD3S is located at an earlier position (771 bp) compared to FSD3 (792 bp). Consequently, the FSD3S mRNA encodes a shorter protein composed of 256 amino acids, compared to 263 amino acids in FSD3.

The presence of the unspliced introns also affected the properties of FSD3S (Fig. 1b). When the hydrophobicity of FSD3 and FSD3S were predicted (http://web.expasy. org/protscale/), the C-terminal region, especially the region located between amino acids 230 and 250, differed between FSD3 and FSD3S. The C-terminal region of FSD3S displayed much higher hydrophobicity than that of FSD3, suggesting that FSD3S function might be different from that of FSD3.

\section{Superoxide dismutase activity of FSD3S}

FSD3 encodes iron superoxide dismutase. Because FSD3 and FSD3S proteins have different properties, it was expected that the superoxide dismutase (SOD) activity of FSD3S protein would be different from that of FSD3 protein. To address this, we analyzed SOD activity of 


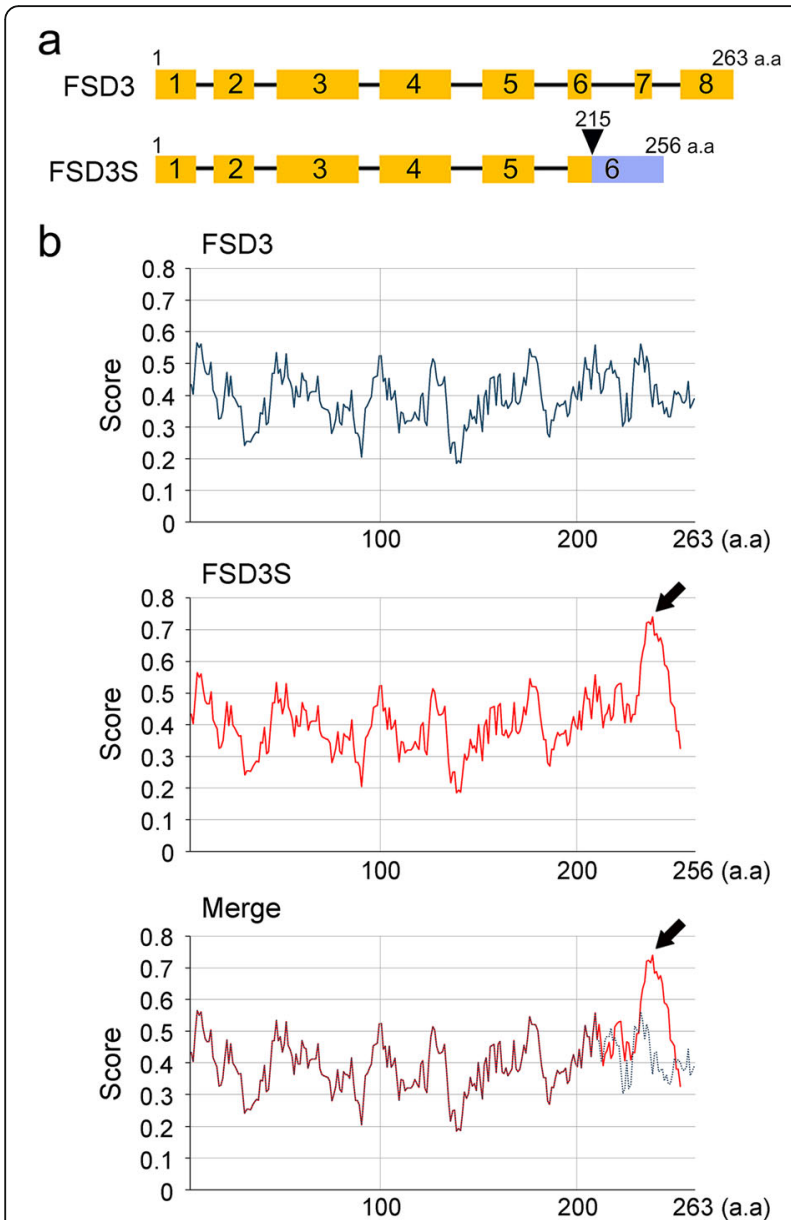

Fig. 1 Identification of FSD3S, a splicing variant of FSD3. a A schematic of the FSD3 and FSD3S mRNA structure. The blue box indicates the C-terminal region of FSD3S, which is composed of different amino acids from those of FSD3, and the arrowhead points to the start of this region. $\mathbf{b}$ The different hydrophobicity between FSD3 and FSD3S. A bioinformatics analysis (http://web.expasy.org/ protscale/) predicted different hydrophobic properties of FSD3 and FSD3S. The black arrows indicate that the C-terminal region of FSD3S has higher hydrophobicity than that of FSD3

FSD3 and FSD3S proteins (Fig. 2). We expressed MBPfused recombinant FSD3 and FSD3S in E. coli and measured their activities with an in-gel SOD activity assay. FSD3S proteins exhibited SOD activity, and the activity of FSD3S was slightly lower or similar to that of FSD3. These observations suggested that the hydrophobic Cterminal region does not have a major effect on the SOD activity of FSD3S.

\section{Subcellular localization of FSD3S}

To test whether the hydrophobic C-terminal region of FSD3S affected its subcellular localization, we generated 35S::FSD3-GFP and 35S::FSD3S-GFP transgenic plants, and analyzed localization of FSD3-GFP and FSD3S-GFP by monitoring fluorescent signals in these transgenic plants.

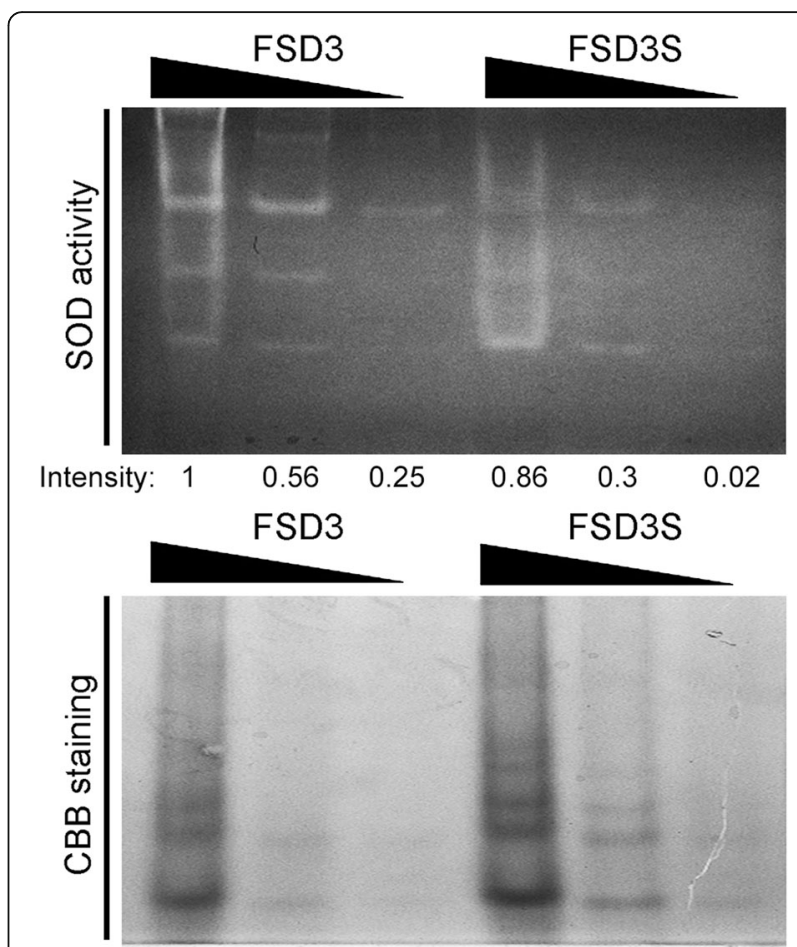

Fig. 2 SOD activity of FSD3S proteins. To analyze SOD activity of FSD3S and FSD3, an in-gel SOD activity assay was performed using MBP-FSD3S and MBP-FSD3. MBP-fused recombinant FSD3S and FSD3 expressed in E. coli were purified with amylose resin. Samples containing sixteen, four, and one microgram of FSD3S or FSD3 protein were loaded on $8 \%$ native-PAGE for the test of SOD activity. Intensity indicates the relative SOD activities of FSD3 and FSD3S, which were quantified using Image I software. Coomassie brilliant blue (CBB) staining was used for loading controls

We tested at least four independent lines of FSD3-GFP and FSD3S-GFP transgenic plants. Despite some differences in the intensity of GFP signals among them, all transgenic plants exhibited green fluorescent signals in their chloroplasts. However, the subcellular localization patterns of the fluorescent signals differed between 35S::FSD3-GFP and 35S::FSD3S-GFP plants (Fig. 3). Consistent with a previous study by Myouga et al. [20], the fluorescent signals of FSD3 proteins appeared as dot-like structures in the chloroplasts (Fig. 3). A co-localization test using the nucleoid-associated protein PEND (PEND-CFP) [42] and FSD3 (FSD3-GFP) showed that CFP and GFP signals were in the same location in the chloroplasts (Additional file 1: Figure S2). This showed that FSD3 localizes to the nucleoids, where the PAPs and PEP complex act. However, 35S:::FSD3S-GFP did not exhibit the dot-shaped signals in chloroplasts, and the fluorescent signals of FSD3S proteins tended to be distributed throughout the chloroplasts (Fig. 3). These observations suggested that FSD3 localizes to chloroplast nucleoids but FSD3S does not. These findings suggested that the hydrophobic C-terminal region of FSD3S affects the localization of FSD3S. 

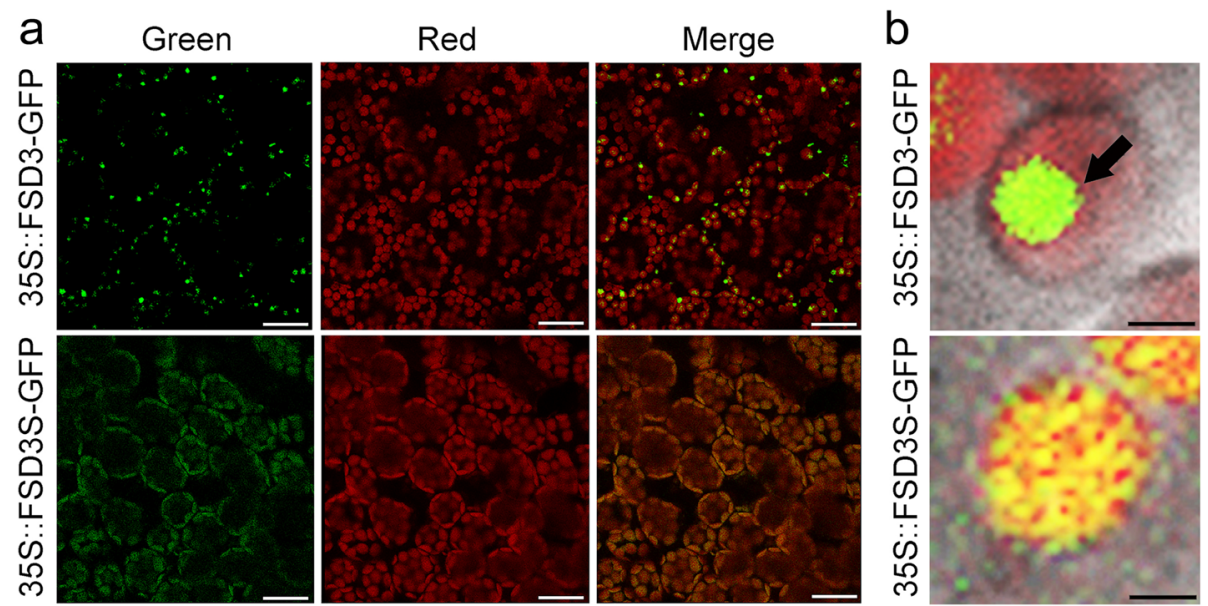

Fig. 3 FSD3 localizes to chloroplast nucleoids, but FSD3S does not. a Subcellular localization of FSD3 and FSD3S was analyzed by visualizing the green fluorescent signals in the mesophyll cells of 35S.:FSD3-GFP or 35S::FSD3S-GFP transgenic plants. b High magnification images showing FSD3 and FSD3S localization in chloroplasts. Green and red correspond to GFP signals and auto-fluorescence of chlorophyll, respectively. The black arrow indicates nucleoid-specific localization of FSD3. Scale bars $=20 \mu \mathrm{m}$ in (a) and $2 \mu \mathrm{m}$ in (b)

The hydrophobic C-terminal region of FSD3S contains a transmembrane domain

Because the $\mathrm{N}$-terminal region is identical between FSD3 and FSD3S proteins but the C-terminal region differs, we expected that the hydrophobic C-terminal region of the FSD3S protein might determine the localization of FSD3S. To explore this, we performed bioinformatics analysis to identify some domains that could be responsible for the localization of FSD3S (http://www.cbs.dtu.dk/services/
TMHMM/). This revealed that the hydrophobic region of FSD3S contains a putative TM helix domain, which is conserved in the TM domains of many membrane and transporter proteins of plants and microbes (Fig. 4a-d). These results suggested that FSD3S contains a TM helix domain in its C-terminal region and the TM domain affects FSD3S localization. This finding was further supported by a bioinformatics analysis of OsFSD3 in rice (Additional file 1: Figures S3 and S4). Through a protein BLAST search using
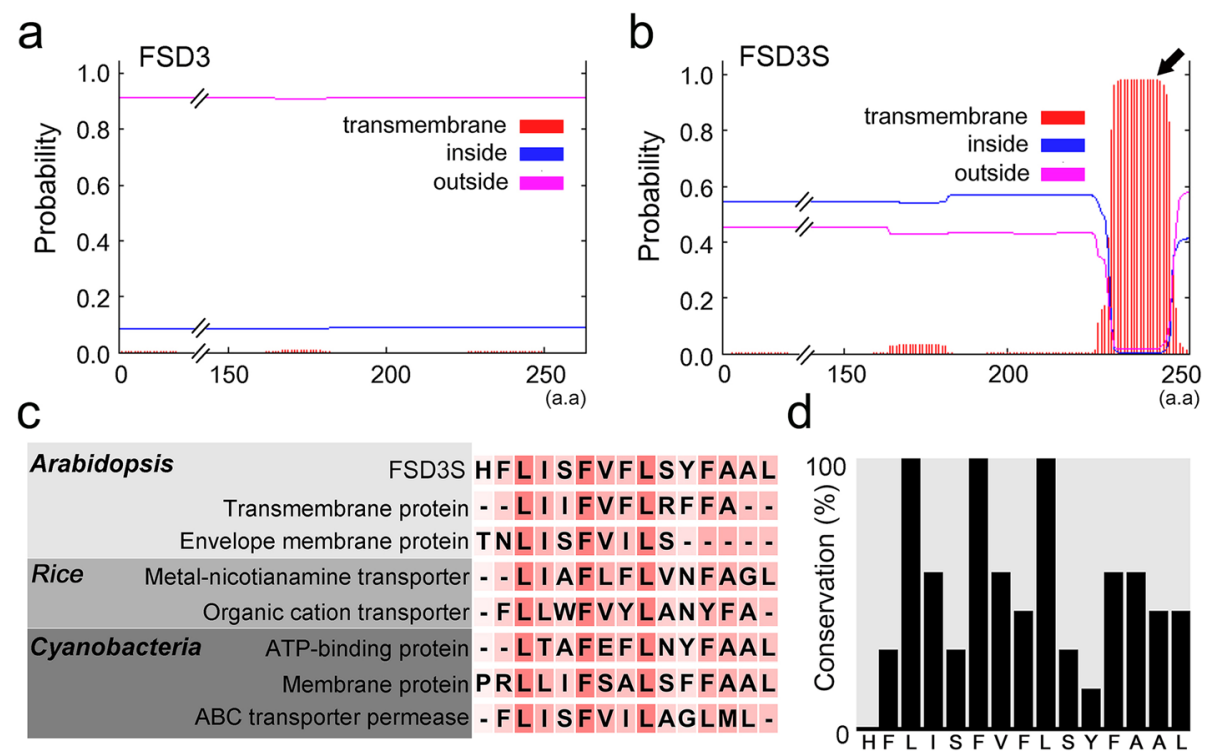

Fig. 4 FSD3S contains a putative transmembrane helix domain. The transmembrane helix domain was predicted by bioinformatics analysis (http://www.cbs.dtu.dk/services/TMHMM/). Unlike FSD3 (a), the existence of a transmembrane helix domain was predicted in the C-terminal regions of FSD3S between the 231 st and 245 th amino acids (b). The black arrow indicates the transmembrane helix domain in the C-terminal regions of FSD3S. A multiple amino acid sequence alignment (c) and histogram (d) show the conservation of the transmembrane helix domains among FSD3S and other membrane or transporter proteins of Arabidopsis, rice, and cyanobacteria. Red boxes in (c) indicate conserved amino acids, with darker red boxes indicating a higher level of conservation 
the full-length amino acid sequence of Arabidopsis FSD3 (http://rice.plantbiology.msu.edu/analyses_search_blast. shtml), we identified a rice homolog of FSD3, LOC_ Os06g05110.1 (OsFSD3) and its splicing variant, LOC_ Os06g05110.3 (OsFSD3S). In addition, the C-terminal region of OsFSD3S protein exhibited higher hydrophobicity than that of OsFSD3, and contains a predicted TM helix domain like FSD3S. These observations indicated that FSD3S has a TM helix domain in its hydrophobic $\mathrm{C}$-terminal region, and the TM domain is involved in the localization of FSD3S.

\section{FSD3S tends to localize at the chloroplast membrane}

To further understand the function of the TM domain in FSD3S localization, we generated transgenic plants expressing GFP-fused FSD3S that lacked the TM domain (FSD3S $\triangle \mathrm{TM}-\mathrm{GFP}$ ), and analyzed the fluorescent signals of FSD3S $\triangle T M$ proteins in chloroplasts. Similar to the 35S:: FSD3S plants in which GFP signals do not localize to nucleoids, 35S::FSD3SATM-GFP plants did not exhibit the dotshaped signals in chloroplasts, and the fluorescent signals were diffuse and found throughout the chloroplasts (Fig. 5).
However, FSD3S-GFP signals were observed along the stoma-forming membrane of the guard cells, while FSD3S $\triangle$ TM-GFP signals were not (Fig. 5a; Additional file 1: Figure S5). These results suggested that the TM domain affects FSD3S localization, and FSD3S with the TM domain tends to localize to the membrane. To further explore the localization of FSD3S in chloroplasts, we performed a series of optical sections using the z-stack function of the confocal microscope. This approach revealed that the localization pattern of FSD3S $\triangle T M$ is different from that of FSD3S proteins (Fig. 5b, c); FSD3S-GFP signals tended to localize to the chloroplast membranes but the FSD3S $\Delta$ TM-GFP signals tended to localize diffusely throughout chloroplasts. These observations suggested that the TM domain of FSD3S promotes FSD3S localization to the chloroplast membrane. This finding was supported by western blotting assays using proteins extracted from 35S::FSD3S-GFP and 35S::FSD3 $\triangle$ TM-GFP chloroplasts and GFP antibody (Additional file 1: Figure S6). Both FSD3 and FSD3S proteins were detected in the soluble factions. However, FSD3S proteins with the TM domain were also detected in insoluble
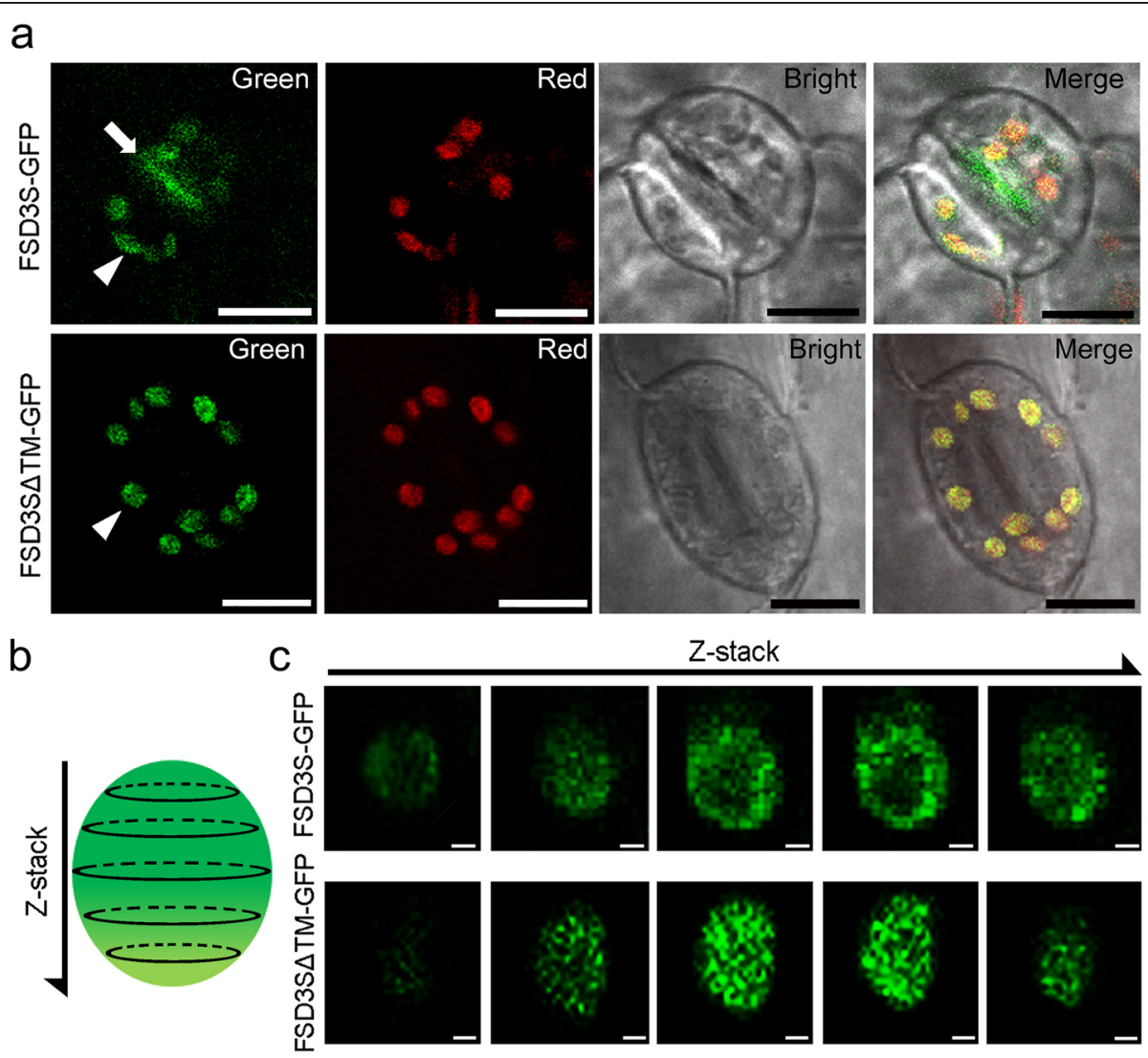

Z-stack
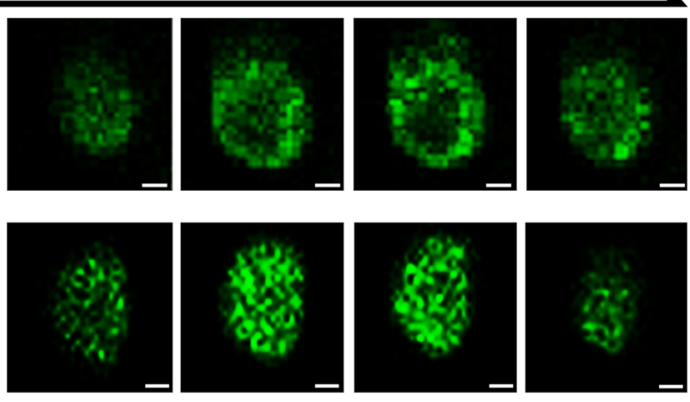

Fig. 5 FSD3S tends to be localized to the chloroplast membrane. a Visualization of subcellular localization of FSD3S and FSD3S $\Delta$ TM proteins lacking the transmembrane helix domain in the guard cells of 35S::FSD3S-GFP and 35S::FSD3SATM-GFP plants. Green and red fluorescence correspond to GFP signals and auto-fluorescence of chlorophyll in chloroplasts, respectively. Bright indicates bright-field images. $\mathbf{b}$ A schematic of a series of optical sections (Z-stack) of chloroplasts using a confocal microscope. Dotted lines indicate longitudinal positions where confocal optical cross-sectioning was performed. c A series of z-stack images showing the fluorescent signals of FSD3S-GFP (top) and FSD3S $\triangle T$ TM-GFP (bottom) inside chloroplasts. Scale bars $=20 \mu \mathrm{m}$ in (a) and $1 \mu \mathrm{m}$ in (b) 
fractions, unlike FSD3 $\Delta T M$. This suggested that the FSD3S protein with a single TM domain has an affinity to localize to the chloroplast membrane but can localize in the chloroplast stroma.

\section{Overexpression of FSD3S reduces expression of PEP- dependent genes}

To understand the function of FSD3S in chloroplast development, we generated FSD3S-overexpressing transgenic plants (Additional file 1: Figure S7). The transgenic plants overexpressing FSD3S were smaller in size than the wildtype plants grown at the same growth conditions (Fig. 6a, b). Overexpression of FSD3S also affected chlorophyll contents and photosynthetic activity (Fig. 6c, d). The chlorophyll contents in the 35S::FSD3S transgenic plants were approximately $15 \%$ lower than those of the wild type grown at the same conditions. Also, the photosynthetic activity in the FSD3S-overexpression plants was approximately $6 \%$ lower than that of the wild-type plants. These observations indicated that FSD3S negatively affects chloroplast development, and the finding that expression of FSD $3 S$ does not rescue the $f s d 3$ mutant phenotype supported this (Additional file 1: Figure S8). In addition, a reduction in plant growth and photosynthetic activity was also seen in the FSD3S-GFP and FSD3SATM-GFP overexpressing plants (Additional file 1: Figure S9). This suggested that the reduction is induced by FSD3S proteins accumulated in the stroma.

Because PAPs determine the activity of the PEP complex, which regulates expression of photosynthetic genes, it was expected that overexpression of FSD3S would affect the expression of photosynthetic genes. To explore FSD3S function in photosynthetic activity, we analyzed the expression of PEP-dependent and NEP-dependent chloroplast genes in $35 S$ :::FSD3S transgenic plants (Fig. 7a). Expression of the
PEP-dependent genes $r b c L$, $p s b A$, and $p s a B$ were downregulated in 35S::FSD3S transgenic plants, whereas the expression of NEP-dependent $r p o B$ was similar or slightly higher compared to wild-type plants. These indicated that FSD3S negatively regulates the expression of PEP-dependent chloroplast genes, suggesting that the negative regulation of PEP-dependent photosynthetic genes is involved in the reduction of photosynthetic activity by FSD3S.

Furthermore, when we analyzed the chloroplast ultrastructure of wild-type and 35S::FSD3S plants grown in the same growth conditions, FSD3S-overexpressing transgenic plants formed more plastoglobuli in their chloroplasts than wild-type plants (Fig. 7b; Additional file 1: Figure S10). Since formation of plastoglobuli is promoted along with senescence [43, 44], we hypothesized that overexpression of FSD3S affects senescence. Although there was not an obvious difference in senescence between wild-type and 35S::FSD3S plants, we found that FSD3S overexpression promotes expression of the senescence-associated gene SAG12 whose expression is linked to senescence [45, 46]. In 5-week-old leaves, SAG12 expression was higher in 35S::FSD3S than that in wild-type plants (Fig. 7c). This suggested that FSD $3 S$ negatively regulates chloroplast development and is involved in senescence.

This finding was supported by the expression pattern of FSD3S (Additional file 1: Figure S11). The transcript level of FSD3S was higher in 10-week-old senescent leaves than in 3-week-old young leaves, whereas the transcript level of FSD3 was higher in 3-week-old young leaves than in 10-week-old senescent leaves. Consequently, the transcript level of FSD3S was approximately 20 -fold lower than that of FSD3 in young leaves, but around 2-fold lower in old leaves. These results supported the idea that FSD3 and FSD3S have different
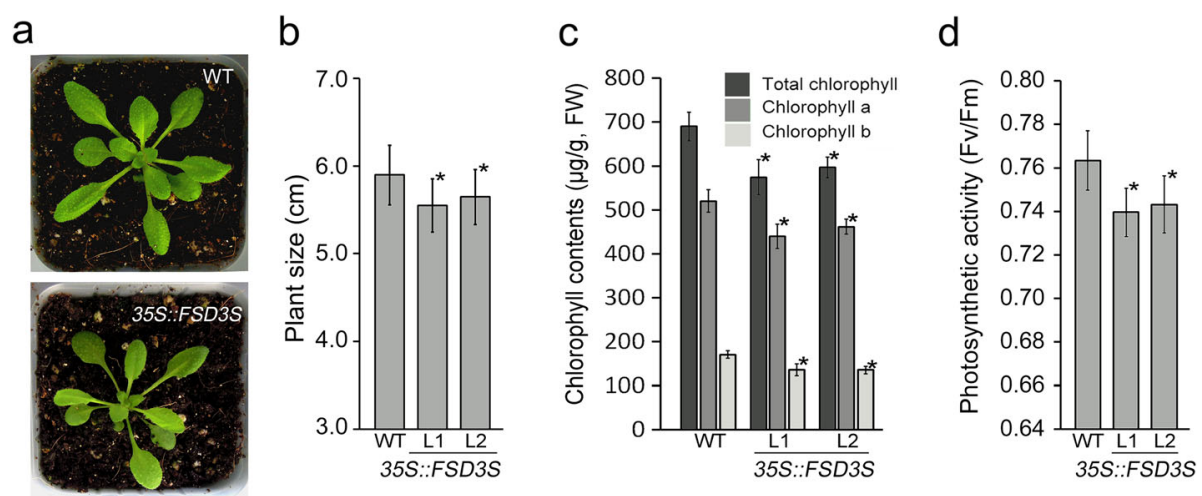

Fig. 6 Overexpression of FSD3S reduces photosynthetic activity. a Images of wild-type and 35S.:.FSD3S plants grown in soil for 5 weeks. $\mathbf{b}$ Quantification of plant size of the 5-week-old wild-type and 35S.:.FSD3S plants ( $n>22$ ). c Quantification of chlorophyll contents in these plants (c) (the number of biological repeats, $n=3$ ). $\mathbf{d}$ Measurement of photosynthetic activity (the number of leaves tested, $n>20$ ). Error bars indicate SD. $\mathrm{L} 1$ and 2 indicate two independent lines of 35S:.FSD3S transgenic plants. Asterisks show statistically significant differences between the indicated samples ( $p$ value $<0.01$, Student's $t$-test) 

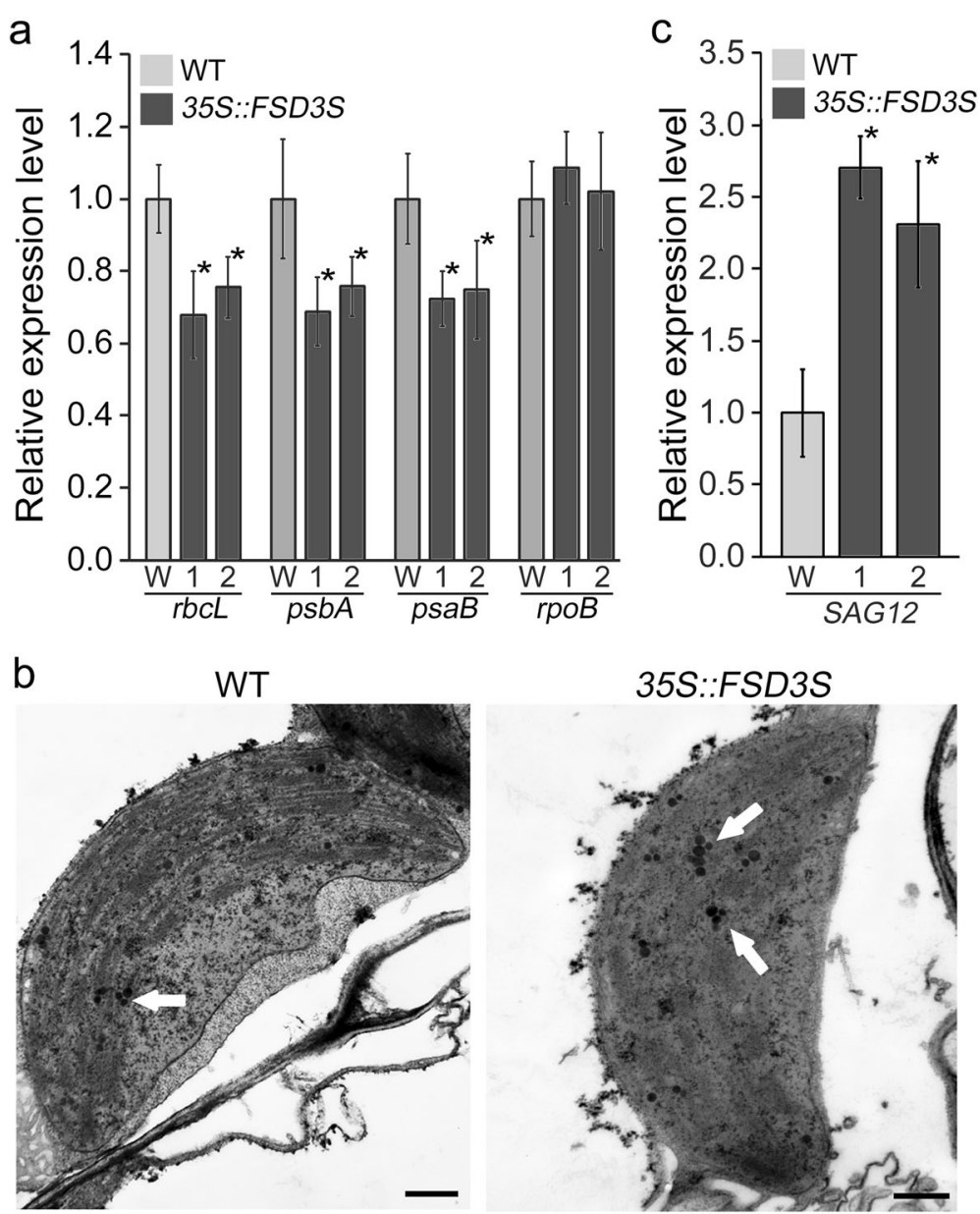

Fig. 7 Overexpression of FSD3S downregulates expression of PEP-dependent genes. a Expression levels of PEP-dependent rbcL, psbA, and psaB, and NEP-dependent rpoB in wild-type and 35S.:.FSD3S plants grown in soil for 5 weeks. b Chloroplast structure of 5-week-old wild-type and 35S::FSD3S plants (line 1) were analyzed using ultra-microsectioning and TEM. c Expression levels of SAG12 in these plants. Expression levels were analyzed by qRT-PCR. Data represent mean values of three biological replicates, and error bars indicate SD. Asterisks indicate statistically significant differences between the corresponding samples and their controls ( $p$ value $<0.01$, Student's $t$-test). W, 1 and 2 indicate Col-0 and the independent lines of the transgenic plants.

functions in chloroplast development, and suggested that FSD3S negatively regulates chloroplast development.

\section{Overexpression of FSD3S does not affect ROS level}

When the levels of reactive oxygen species (ROS) were analyzed in wild-type and 35S::FSD3S plants by CMH2DCFDA staining, a ROS-sensitive dye with good intracellular retention [47], we observed no obvious differences in the CM-H2DCFDA staining (Fig. 8a), suggesting that ROS levels are similar between these plants. To further test this, we stained these plants with nitroblue tetrazolium (NBT), and visualized their signals. Similar to the CM-H2DCFDA staining, the plants all showed similar intensities of the NBT staining (Fig. 8b), suggesting that overexpression of FSD3S does not affect ROS level, and the SOD activity of FSD3S might be not involved in the negative function of FSD3S in photosynthetic activity.
Instead, we found that FSD3 and FSD3S proteins interact with pTAC10, a key PAP of PEP complex $[18,26,27]$ (Fig. 8c). Because formation of PEP complex is a key process to control the activity of PEP and the transcription of photosynthesis-related genes [3], this suggested that the FSD3S-pTAC10 interaction might be involved in the negative function of FSD3S in photosynthetic activity.

\section{Discussion}

PEP interacts with PAPs to form a functional transcription complex. A recent model proposed that PAPs play an essential role in the expression of chloroplast genes and development of chloroplasts by regulating the structural establishment of the PEP complex through PAPPAP or PAP-PEP interactions [3, 25]. This model is supported by many molecular and genetic studies showing that each PAP interacts extensively with other PAPs 

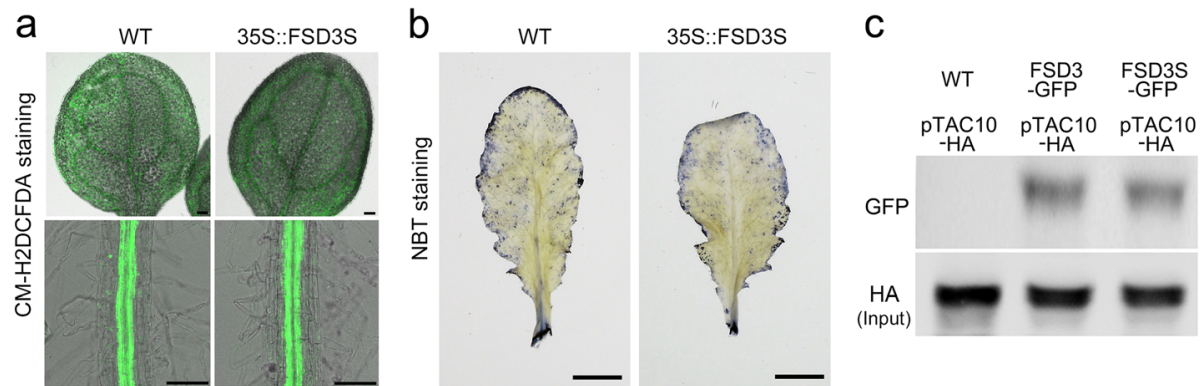

Fig. 8 Analysis of ROS accumulation by $\mathrm{CM}-\mathrm{H}_{2}$ DCFDA and NBT staining. ROS accumulation was analyzed in wild-type and 35S::FSD3S plants by CM- $\mathrm{H}_{2}$ DCFDA (a) and NBT staining (b). CM- $\mathrm{H}_{2}$ DCFDA staining was performed in the leaves and roots of wild-type and 35S::FSD3S plants grown on 1/2 MS media for 2 weeks. For NBT staining, 6-week-old rosette leaves collected from the indicated plants were used. c Interaction between FSD3S and pTAC10. A Co-IP result showing that both FSD3 and FSD3S interact with pTAC10. Protoplasts isolated 35S::FSD3-GFP and 35S::.FSD3SGFP plants were transformed with 355::pTAC10-HA plasmid. HA antibody was used to pull down immune complex and GFP antibody was used to detect interaction of pTAC10-FSD3 or pTAC10-FSD3S. Scale bars $=100 \mu \mathrm{m}$ in (a) and $2 \mathrm{~mm}$ in (b)

or with PEP, and mutations in PAPs or PEP result in defects in chloroplast development [13, 16-19, 21-24, 48]. For example, FSD3/PAP4 interacts with other PAPs such as $\mathrm{pTAC10/ \textrm {PAP } 3}$ and FSD2/PAP9, and $f s d 3$ mutant plants show defects in chloroplast development $[20,26]$.

Alternative splicing can produce two or more proteins from a single gene, and these proteins can have different functions [40]. All 12 Arabidopsis PAP genes contain introns, suggesting that variant PAPs might be involved in the formation of the PEP complex and chloroplast development. pTAC12/PAP5 encodes two different protein isoforms in maize and both variant proteins assemble into the PEP complex [27], although the pTAC12/PAP5 isoforms are not produced by alternative splicing, but by post-transcriptional processes such as alternative initiation of translation or differential proteolytic cleavage. In this study, we identified FSD3S, a splicing variant of FSD3. FSD3 and FSD3S encode proteins with identical $\mathrm{N}$-termini, but different $\mathrm{C}$-termini. We showed that the C-terminal regions of FSD3 and FSD3S are involved in their subcellular localization in chloroplasts. The plants expressing FSD3-GFP specifically exhibited fluorescent signals at chloroplast nucleoids where PAPs and the PEP complex act for transcription of chloroplast genes, whereas the FSD3S-GFP plants did not show a signal in the nucleoid. The distinct localization of FSD3S could explain why FSD3S cannot rescue the $f s d 3$ knock-out mutant phenotype.

In this study we also showed that overexpression of FSD3S reduces photosynthetic activity. The finding that overexpression of FSD3S downregulates the transcript levels of PEPdependent genes involved in photosynthesis suggests that the reduction of photosynthetic activity in FSD3S-overexpressing plants might be caused by the reduction of PEP activity responsible for the transcription of photosynthesis genes. Our optical z-stack and western blot results showed that FSD3S proteins with a single TM domain are located in the chloroplast membrane and stroma. Because the reduction in photosynthetic activity was also induced by overexpression of FSD3S-GFP and FSD3SATM-GFP, these observations suggest that FSD3S accumulated in the chloroplast stroma might be responsible for the negative regulation. The molecular mechanisms underlying this process are unknown. However, it is unlikely that the SOD activity of FSD3S would be involved in this process, because there was no obvious difference in ROS levels between wild-type and FSD3S-overexpressing plants. Formation of the PEP complex through PEP-PAP or PAP-PAP interaction is a key process to control the activity of PEP [3]. Previous studies revealed that FSD3 interacts with other PAPs such as FSD2/ PAP9 and pTAC10/PAP3 [20, 26]. This suggests that FSD3S proteins might negatively affect PEP activity by disrupting formation of the PEP complex, and the coimmunoprecipitation results showing that FSD3 and FSD3S interact with pTAC10/PAP3 partially support this idea. Further molecular and genetic approaches will expand our understanding of the mechanisms underlying this process.

\section{Conclusions}

Since PAPs regulates expression of chloroplast genes, localization of PAPs to chloroplast nucleoids where the PEP complex acts is crucial for their function. In this study, we identified FSD3S, an isoform of FSD3. The Nterminal regions upstream of the 215th amino acid are identical between FSD3 and FSD3S, but the amino acid sequences of their C-terminal regions are completely different. The plants expressing FSD3-GFP showed specific localization of FSD3 to chloroplast nucleoids. However, FSD3S, whose C-terminal region is composed of completely different amino acid sequence from that of FSD3, did not localize to the nucleoid. Furthermore, the Cterminal region contains a TM domain and promotes FSD3S localization to the chloroplast membrane. These results indicated that the $\mathrm{C}$-terminal region of FSD3 is 
responsible for the nucleoid-specific localization of FSD3, supporting the theory that the $\mathrm{C}$-terminal region of FSD3 is essential for FSD3 function in chloroplast development. These observations provide an explanation why FSD3S cannot rescue the $f s d 3$ knock-out mutant phenotype. Together with the findings that overexpression of FSD $3 S$ reduces photosynthetic activity and expression of PEP-dependent chloroplast genes, these suggest that FSD3S negatively regulates chloroplast development.

\section{Methods}

\section{Plant materials and growth conditions}

Arabidopsis thaliana ecotype Columbia (Col-0) was used as a control in this study. The $f s d 3-1$ mutant (Salk 103228) previously described in Myouga et al. [20] was obtained from the Arabidopsis Biological Resource Center. Seeds were sterilized and plated on 1/2-strength Murashige and Skoog (1/2x MS) solid media. After 2 days of vernalization at $4{ }^{\circ} \mathrm{C}$ in darkness, plants were grown in a growth chamber with a light regime of $16 / 8$ h (light/dark) at $22^{\circ} \mathrm{C}$. The seedlings were transferred into soil for analyses of mature plants. For the growth in continuous light or dark conditions, plants were grown in the chamber at $22^{\circ} \mathrm{C}$.

\section{Construction of recombinant DNA plasmids for transgenic plants}

The GATEWAY system (Invitrogen) was used for construction of the recombinant DNA plasmids. For the construction of the $35 S:: F S D 3 S$ construct, full-length FSD3S cDNA was amplified by RT-PCR from Arabidopsis total RNA. The CDNA was inserted into the pDONR221 vector (Invitrogen) by the BP reaction. The pENTRY clones were then recombined into the modified pMDC plant binary vector carrying the $35 \mathrm{~S}$ promoter by the LR reaction. For the construction of $35 S:: F S D 3 S-G F P$ and 35S::FSD3S $\triangle T M-G F P$, each pENTRY clone containing FSD3S, or FSD $3 S \triangle T M$ cDNA lacking the stop codon was recombined in-frame with the $35 \mathrm{~S}$ promoter and GFP by the LR reaction. Primer sequences are listed in Additional file 1: Table S1.

\section{Ultra-microsectioning and transmission electron microscopy}

For the analysis of chloroplast ultrastructure, ultramicrosectioning was performed as described previously by Motohashi et al. (2001) with slight modifications [49]. Leaves collected from the indicated plants were fixed for 1 day at room temperature using fixing solution 1 ( 0.86 M Na-P [pH 7.2], 1\% glutaraldehyde, and 1\% paraformaldehyde). The samples were washed 3 times using washing solution $(0.137 \mathrm{M} \mathrm{Na}-\mathrm{P}$ [pH 7.2]) and then treated with a second round of fixation with fixing solution 2
(0.86 M Na-P [pH 7.2], 2\% osmium tetroxide) for $1 \mathrm{~h}$ at room temperature. After being washed three times, the samples were dehydrated with an acetone gradient (25, 50, 75, and $100 \%$ in $\left.\mathrm{ddH}_{2} \mathrm{O}(\mathrm{v} / \mathrm{v})\right)$ for $1 \mathrm{~h}$ each and then incubated in absolute acetone overnight. The dehydrated samples were sequentially incubated in a gradient of Spurr resin (Sigma) $(25,50,75$, and $100 \%$ in acetone (v/ v)) for $2 \mathrm{~h}$ each and in absolute Spurr resin overnight. For solidification, the samples were placed in a mold at $65^{\circ} \mathrm{C}$ for 2 days. Sections $(80 \mathrm{~nm})$ were taken with an ultramicrotome (EM UC7, Leica). Images were captured with a transmission electron microscope (TEM), JEM1010.

\section{Measurement of chlorophyll content and photosynthetic activity}

The chlorophyll contents were measured in 5-week-old Col-0 and FSD3S-OX as described previously by Sumanta et al. [50]. Fresh leaves $(0.75 \mathrm{~g})$ were homogenized with a plant tissue homogenizer with $15 \mathrm{ml}$ of $95 \%$ ethanol ( $\mathrm{v} / \mathrm{v}$ in $\left.\mathrm{ddH}_{2} \mathrm{O}\right)$. The homogenized samples were centrifuged at $12,000 \mathrm{x}$ g for $15 \mathrm{~min}$ at $4{ }^{\circ} \mathrm{C}$. The supernatants were diluted 10 -fold using $95 \%$ ethanol. Chlorophyll contents were measured with a UV/visible spectrophotometer (OPTIZEN POP, Mecasys). For the measurement of photosynthetic activity in these transgenic plants, leaf disks were collected from 6th through 8 th leaves of the 5-week-old Col-0 and the indicated transgenic plants. Leaf disks were kept in the dark for $30 \mathrm{~min}$ before measuring. The $\mathrm{Fv} / \mathrm{Fm}$ values of the leaves were determined with a pulse modulation fluorometer (mini-PAM, Walz, Germany).

\section{In-gel SOD activity assay}

The FSD3 and FSD3S cDNAs were fused into the expression vector pMBP-DC using gateway system (Invitrogen). Each construct was introduced into Escherichia coli BL21(DE3) pLysS codon plus RIL strain, respectively. Expression of the recombinant proteins was induced by $1 \mathrm{mM}$ isopropyl- $\beta$-D-thiogalactoside at $18^{\circ} \mathrm{C}$ for $14 \mathrm{~h}$. Crude extracts were purified with amylose resin (NEB). After washing four times with the extraction buffer $(20 \mathrm{mM}$ Tris- $\mathrm{HCl}$ [pH 7.4], $200 \mathrm{mM} \mathrm{NaCl}, 1 \mathrm{mM}$ EDTA and $10 \mathrm{mM} \beta$-mercaptoethanol), elution was performed with the extraction buffer containing $10 \mathrm{mM}$ maltose. The SOD activity of the proteins was analyzed as described previously by Beauchamp and Fridovich (1971) and Myouga et al. (2008) [20, 51]. Each protein was loaded onto native-PAGE. The gel was washed with $\mathrm{ddH}_{2} \mathrm{O}$ three times, and then incubated with NBT solution $\left(0.1 \% \mathrm{NBT}\right.$ in $\left.\mathrm{ddH}_{2} \mathrm{O}(\mathrm{w} / \mathrm{v})\right)$ in the dark with gentle shaking for $15 \mathrm{~min}$. After washing with $\mathrm{ddH}_{2} \mathrm{O}$, the gel was immersed in riboflavin solution $(0.028 \mathrm{mM}$ riboflavin and $28 \mathrm{mM}$ TEMED in $0.1 \mathrm{M}$ potassium phosphate 
buffer [pH 7.0]) for $15 \mathrm{~min}$ and rinsed with $\mathrm{ddH}_{2} \mathrm{O}$. The gel was illuminated with a white light box to initiate the photochemical reaction. Image J software was used for quantification of the SOD activity.

\section{Purification and fractionation of chloroplast proteins}

Intact chloroplasts were isolated from wild-type, 35S:: FSD3S-GFP, and 35S::FSD3S $\triangle T M-G F P$ plants using the Minute Chloroplast Isolation Kit (Invent Biotechnologies). The chloroplasts were lysed osmotically by suspending them with $50 \mathrm{mM}$ Tris- $\mathrm{Cl}$ [pH 7.5]. The samples were vortexed vigorously and then centrifuged at $10,000 \mathrm{x}$ g for 20 $\min$ at $4{ }^{\circ} \mathrm{C}$. The supernatants were used as the soluble fraction. For the preparation of the insoluble fraction, the remaining pellets were suspended and boiled for $5 \mathrm{~min}$ with 2x Laemmli Sample Buffer (Bio-Rad). The proteins were loaded into $10 \%$ SDS-polyacrylamide gels and then transferred to a polyvinylidene fluoride membrane. To detect FSD3S-GFP and FSD3S $\triangle$ TM-GFP, immunoblot assay was performed using GFP polyclonal antibodies (Santa Cruz) and anti-rabbit HRP-linked secondary antibodies (Thermo Fisher). Western blot signals were detected with Amersham ECL prime (GE Healthcare).

\section{Quantitative RT-PCR}

Quantitative RT-PCR analyses were performed using total RNA extracted from the indicated plants. Extraction of total RNA was carried out using the RNeasy plant mini-prep kit (Qiagen) and DNase was treated for 15 min according to the manufacturer's instructions. For cDNA synthesis, $20 \mu \mathrm{L}$ reactions were performed using $2 \mu \mathrm{g}$ of total RNA and Superscript III reverse transcriptase (Invitrogen). For quantitative PCR, a LightCycler 480 with SYBR GREEN I Master Mix (Roche) was used. PCR and fluorescence detection were performed using a LightCycler NANO Real-Time PCR machine (Roche). PCR conditions were programmed according to the manufacturer's instructions (initial denaturation at $95^{\circ} \mathrm{C}$ for $5 \mathrm{~min}$ followed by 45 cycles of denaturation at $95^{\circ} \mathrm{C}$ for $10 \mathrm{~s}$, annealing at $60^{\circ} \mathrm{C}$ for $10 \mathrm{~s}$, and extension at $72{ }^{\circ} \mathrm{C}$ for $10 \mathrm{~s}$ ). Expression levels were analyzed using three technical replicates. AtACT2 (At3g18780) was used as an internal control. Three technical replicates of the qRT-PCRs were performed using three biological replicates. Primer sequence information is listed in Additional file 1: Table S1.

\section{Co-immunoprecipitation and co-localization assays}

Protoplasts were isolated from wild-type, 35S::FSD3GFP, and 35S::FSD3S-GFP plants, and transformed with the 35S::pTAC10-HA plasmid. To construct the 35S:: pTAC10-HA plasmid, $p T A C 10$ cDNAs were introduced into BamHI/NotI-digested pE2C plasmid for pTAC10HA using the Gilson assembly system (NEB). This entry clone was inserted into the pMDC plasmid by the LR reaction. The co-immunoprecipitation assay was performed as described by Chang et al. (2017) with slight modification [26]. For the analysis of co-localization of FSD3-GFP and PEND-CFP, protoplasts isolated from 35S::FSD3-GFP plants were used. For the construction of $35 S:: P E N D-C F P$, a PEND cDNA encoding the $\mathrm{N}$ terminal 88-amino acid sequence [42] was amplified and introduced into the BamHI-digested pHBT-CFP plasmids. Fluorescent signals in the protoplasts were detected with a confocal microscope (STED, Leica).

\section{Histochemical detection of ROS by $\mathrm{CM}-\mathrm{H}_{2}$ DCFDA and NBT staining}

To visualize ROS accumulation in the leaves, CM$\mathrm{H}_{2}$ DCFDA staining was performed as previously described by Foreman et al. (2003) with slight modification [47]. Two-week-old wild-type and 35S::FSD3S plants were incubated for $1 \mathrm{~h}$ at $4{ }^{\circ} \mathrm{C}$ in $10 \mu \mathrm{M}$ CM- $\mathrm{H}_{2}$ DCFDA solution. The samples were washed with $0.1 \mathrm{mM} \mathrm{KCl}$ and $0.1 \mathrm{mM}$ $\mathrm{CaCl}_{2}$ (pH 6.0) and then incubated for $1 \mathrm{~h}$ at RT. CM$\mathrm{H}_{2}$ DCFDA signals were visualized using a confocal microscope (STED, Leica). NBT staining was performed as described previously by Hoffmann et al. (2005) with slight modifications [52]. Mature rosette leaves collected from wild-type and 35S::FSD3S plants grown in soil for 6 weeks were treated with NBT staining solution $(6 \mathrm{mM} \mathrm{NBT}, 2.7$ $\mathrm{mM} \mathrm{KCl}, 1.8 \mathrm{mM} \mathrm{KH} \mathrm{PO}_{4}, 10 \mathrm{mM} \mathrm{NaH} \mathrm{NO}_{4}$, and 137 $\mathrm{mM} \mathrm{NaCl}$ [pH 7.1]). After $10 \mathrm{~min}$ of vacuum infiltration in the dark, the samples were exposed to light for $20 \mathrm{~min}$ at $\mathrm{RT}$ and then transferred into absolute ethanol to remove the chlorophyll. NBT staining images were captured using a digital camera, Coolpix p300 (Nikon).

\section{Supplementary information}

Supplementary information accompanies this paper at https://doi.org/10. 1186/s12870-019-2128-9.

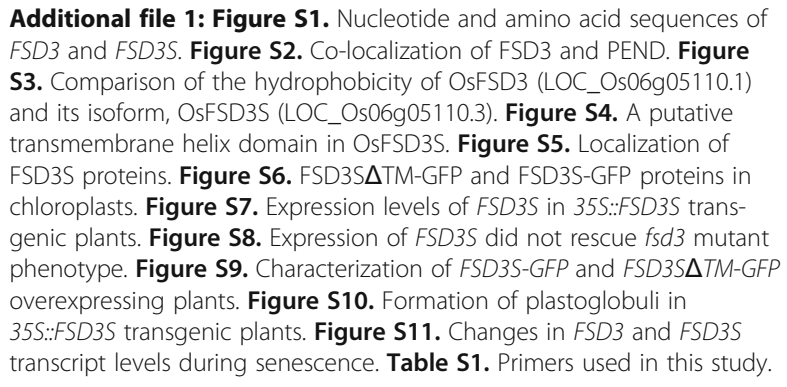

Additional file 1: Figure S1. Nucleotide and amino acid sequences of FSD3 and FSD3S. Figure S2. Co-localization of FSD3 and PEND. Figure S3. Comparison of the hydrophobicity of OsFSD3 (LOC_Os06g05110.1) and its isoform, OsFSD3S (LOC_Os06g05110.3). Figure S4. A putative transmembrane helix domain in OsFSD3S. Figure S5. Localization of FSD3S proteins. Figure S6. FSD3S $\triangle T$ TM-GFP and FSD3S-GFP proteins in chloroplasts. Figure S7. Expression levels of FSD3S in 35S::FSD3S transgenic plants. Figure S8. Expression of FSD3S did not rescue $f s d 3$ mutant phenotype. Figure S9. Characterization of FSD3S-GFP and FSD3SATM-GFP overexpressing plants. Figure S10. Formation of plastoglobuli in 35S::FSD3S transgenic plants. Figure S11. Changes in FSD3 and FSD3S transcript levels during senescence. Table S1. Primers used in this study.

\section{Abbreviations}

FSD: Iron superoxide dismutase; PAP: Plastid-encoded RNA polymeraseassociated protein; PEP: Plastid-encoded RNA polymerase; qRTPCR: Quantitative reverse transcription polymerase chain reaction; SOD: Superoxide dismutase 


\section{Acknowledgements}

We thank Sun Hyun Chang and Tae Young Um (Seoul National University) for technical assistance for ultra-microsectioning/TEM and SOD activity assay.

\section{Authors' contributions}

GJ conceived the original screening and research plans; GJ and YC supervised the experiments. SL performed most of the experiments. GJ, JK and $Y C$ designed the experiments and analyzed the data; GJ and YC conceived the project and wrote the article with contributions of all the authors; YJ and JK complemented the writing. All authors read and approved the final manuscript.

\section{Funding}

This work was carried out with the support of the Cooperative Research Program for Agriculture Science \& Technology Development (Project No. PJ01323901 and PJ01364301) Rural Development Administration, Republic of Korea, and the National Research Foundation of Korea Grant funded by the Korean Government (MOE) [NRF-2019R1A2C1007103].

\section{Availability of data and materials}

Sequence data from this article can be found in the Arabidopsis Genome Initiative or GenBank/EMBL databases under the following accession numbers: FSD3 (At5g23310), FSD3S (KY471384), PEND (At3g52170), SAG12 (At5g45890), rpoA (AtCg00740), rpoB (AtCg00190), rbcL (AtCg00490), psbA (AtCg00020), psaB (AtCg00340) and ACT2 (At3g18780). The data and materials used in this study are available from the corresponding author on reasonable request.

\section{Ethics approval and consent to participate}

Not applicable.

\section{Consent for publication}

Not applicable.

\section{Competing interests}

The authors declare that they have no competing interests.

\section{Author details}

${ }^{1}$ School of Biological Sciences and Technology, Chonnam National University, Gwangju 61186, Republic of Korea. ${ }^{2}$ Graduate School of International Agricultural Technology and Crop Biotechnology Institute/ Green BioScience and Technology, Seoul National University, Pyeongchang 25354, Republic of Korea. ${ }^{3}$ Department of Agricultural Biotechnology and Research Institute of Agriculture and Life Sciences, Seoul National University, Seoul 08826, Republic of Korea. ${ }^{4}$ The National Academy of Sciences, Seoul 06579, Republic of Korea.

Received: 16 December 2018 Accepted: 8 November 2019 Published online: 27 November 2019

\section{References}

1. Cahoon AB, Stern DB. Plastid transcription: a menage a trois? Trends Plant Sci. 2001;6(2):45-6

2. Maliga P. Two plastid RNA polymerases of higher plants: an evolving story Trends Plant Sci. 1998;3(1):4-6.

3. Pfalz J, Pfannschmidt T. Essential nucleoid proteins in early chloroplast development. Trends Plant Sci. 2013;18(4):186-94.

4. Zhelyazkova P, Sharma CM, Förstner KU, Liere K, Vogel J, Börner T. The primary transcriptome of barley chloroplasts: numerous noncoding RNAs and the dominating role of the plastid-encoded RNA polymerase. Plant Cell. 2012:24(1):123-36.

5. Börner T, Aleynikova AY, Zubo YO, Kusnetsov W. Chloroplast RNA polymerases: Role in chloroplast biogenesis. Biochim Biophys Acta (BBA)Bioenergetics. 2015;1847(9):761-9.

6. Allison L, Simon L, Maliga P. Deletion of rpoB reveals a second distinct transcription system in plastids of higher plants. EMBO J. 1996;15(11):2802.

7. Legen J, Kemp S, Krause K, Profanter B, Herrmann RG, Maier RM. Comparative analysis of plastid transcription profiles of entire plastid chromosomes from tobacco attributed to wild-type and PEP-deficient transcription machineries. Plant J. 2002;31(2):171-88.
8. Baba K, Schmidt J, Espinosa-Ruiz A, Villarejo A, Shiina T, Gardeström P, Sane AP, Bhalerao RP. Organellar gene transcription and early seedling development are affected in the rpoT; 2 mutant of Arabidopsis. Plant J. 2004:38(1):38-48.

9. Hricová A, Quesada V, Micol JL. The SCABRA3 nuclear gene encodes the plastid RpoTp RNA polymerase, which is required for chloroplast biogenesis and mesophyll cell proliferation in Arabidopsis. Plant Physiol. 2006;141(3): 942-56.

10. Swiatecka-Hagenbruch M, Emanuel C, Hedtke B, Liere K, Börner T. Impaired function of the phage-type RNA polymerase RpoTp in transcription of chloroplast genes is compensated by a second phage-type RNA polymerase. Nucleic Acids Res. 2008;36(3):785-92.

11. Kühn K, Richter U, Meyer EH, Delannoy E, de Longevialle AF, O'Toole N, Börner T, Millar AH, Small ID, Whelan J. Phage-type RNA polymerase RPOTmp performs gene-specific transcription in mitochondria of Arabidopsis thaliana. Plant Cell. 2009;21(9):2762-79.

12. Yu Q-B, Huang C, Yang Z-N. Nuclear-encoded factors associated with the chloroplast transcription machinery of higher plants. Front Plant Sci. 2014;5:316.

13. Steiner S, Schröter Y, Pfalz J, Pfannschmidt T. Identification of essential subunits in the plastid-encoded RNA polymerase complex reveals building blocks for proper plastid development. Plant Physiol. 2011;157(3):1043-55.

14. Majeran W, Friso G, Asakura Y, Qu X, Huang M, Ponnala L, Watkins KP, Barkan A, Van Wijk KJ. Nucleoid-enriched proteomes in developing plastids and chloroplasts from maize leaves; a new conceptual framework for nucleoid functions. Plant Physiol. 2012;158(1):156-89.

15. Melonek J, Oetke S, Krupinska K. Multifunctionality of plastid nucleoids as revealed by proteome analyses. Biochim Biophys Acta (BBA)-Proteins and Proteomics. 2016;1864(8):1016-38.

16. Pfalz J, Liere K, Kandlbinder A, Dietz K-J, Oelmüller R. pTAC2,-6, and-12 are components of the transcriptionally active plastid chromosome that are required for plastid gene expression. Plant Cell. 2006;18(1):176-97.

17. Yagi $Y$, Ishizaki $Y$, Nakahira $Y$, Tozawa $Y$, Shiina T. Eukaryotic-type plastid nucleoid protein PTAC3 is essential for transcription by the bacterial-type plastid RNA polymerase. Proc Natl Acad Sci. 2012;109(19):7541-6.

18. Williams-Carrier R, Zoschke R, Belcher S, Pfalz J, Barkan A. A major role for the plastid-encoded RNA polymerase complex in the expression of plastid transfer RNAs. Plant Physiol. 2014;164(1):239-48.

19. Chen M, Galvão RM, Li M, Burger B, Bugea J, Bolado J, Chory J. Arabidopsis HEMERA/pTAC12 initiates photomorphogenesis by phytochromes. Cell. 2010;141(7):1230-40.

20. Myouga F, Hosoda C, Umezawa T, lizumi H, Kuromori T, Motohashi R, Shono Y, Nagata N, Ikeuchi M, Shinozaki K. A heterocomplex of iron superoxide dismutases defends chloroplast nucleoids against oxidative stress and is essential for chloroplast development in Arabidopsis. Plant Cell. 2008;20(11):3148-62.

21. Gao Z-P, Yu Q-B, Zhao T-T, Ma Q, Chen G-X, Yang Z-N. A functional component of the transcriptionally active chromosome complex, Arabidopsis PTAC14, interacts with pTAC12/HEMERA and regulates plastid gene expression. Plant Physiol. 2011;157(4):1733-45.

22. Arsova B, Hoja U, Wimmelbacher M, Greiner E, Üstün Ş, Melzer M, Petersen K, Lein W, Börnke F. Plastidial thioredoxin z interacts with two fructokinaselike proteins in a thiol-dependent manner: evidence for an essential role in chloroplast development in Arabidopsis and Nicotiana benthamiana. Plant Cell. 2010:22(5):1498-515.

23. Schröter $Y$, Steiner $S$, Matthäi $K$, Pfannschmidt T. Analysis of oligomeric protein complexes in the chloroplast sub-proteome of nucleic acid-binding proteins from mustard reveals potential redox regulators of plastid gene expression. Proteomics. 2010;10(11):2191-204.

24. Huang C, Yu Q-B, Lv R-H, Yin Q-Q, Chen G-Y, Xu L, Yang Z-N. The reduced plastid-encoded polymerase-dependent plastid gene expression leads to the delayed greening of the Arabidopsis fln2 mutant. PLoS One. 2013;8(9): e73092.

25. Yu QB, Lu Y, Ma Q, Zhao TT, Huang C, Zhao HF, Zhang XL, Lv RH, Yang ZN. TAC7, an essential component of the plastid transcriptionally active chromosome complex, interacts with FLN1, TAC10, TAC12 and TAC14 to regulate chloroplast gene expression in Arabidopsis thaliana. Physiol Plant. 2013:148(3):408-21.

26. Chang SH, Lee S, Um TY, Kim J-K, Do Choi Y, Jang G. pTAC10, a key subunit of plastid-encoded RNA polymerase, promotes chloroplast development. Plant Physiol. 2017;174(1):435-49.

27. Pfalz J, Holtzegel U, Barkan A, Weisheit W, Mittag M, Pfannschmidt T. ZmpTAC12 binds single-stranded nucleic acids and is essential for 
accumulation of the plastid-encoded polymerase complex in maize. New Phytol. 2015;206(3):1024-37.

28. Pilon M, Ravet $\mathrm{K}$, Tapken $\mathrm{W}$. The biogenesis and physiological function of chloroplast superoxide dismutases. Biochim Biophys Acta (BBA)Bioenergetics. 2011;1807(8):989-98.

29. Kliebenstein DJ, Monde R-A, Last RL. Superoxide dismutase in Arabidopsis: an eclectic enzyme family with disparate regulation and protein localization. Plant Physiol. 1998;118(2):637-50.

30. Kleffmann T, Russenberger D, von Zychlinski A, Christopher W, Sjölander K, Gruissem W, Baginsky S. The Arabidopsis thaliana chloroplast proteome reveals pathway abundance and novel protein functions. Curr Biol. 2004;14(5):354-62.

31. Sunkar R, Kapoor A, Zhu J-K. Posttranscriptional induction of two $\mathrm{Cu} / \mathrm{Zn}$ superoxide dismutase genes in Arabidopsis is mediated by downregulation of miR398 and important for oxidative stress tolerance. Plant Cell. 2006; 18(8):2051-65.

32. Rizhsky L, Liang H, Mittler R. The water-water cycle is essential for chloroplast protection in the absence of stress. J Biol Chem. 2003;278(40): 38921-5.

33. Chen Y, Jiang J, Song A, Chen S, Shan H, Luo H, Gu C, Sun J, Zhu L, Fang W. Ambient temperature enhanced freezing tolerance of Chrysanthemum dichrum CdICE1 Arabidopsis via miR398. BMC Biol. 2013;11:121.

34. Filichkin SA, Priest HD, Givan SA, Shen R, Bryant DW, Fox SE, Wong W-K, Mockler TC. Genome-wide mapping of alternative splicing in Arabidopsis thaliana. Genome Res. 2010;20(1):45-58.

35. Chen W-H, Lv G, Lv C, Zeng C, Hu S. Systematic analysis of alternative first exons in plant genomes. BMC Plant Biol. 2007;7(1):55.

36. Jain M, Khurana P, Tyagi AK, Khurana JP. Genome-wide analysis of intronless genes in rice and Arabidopsis. Funct Integr Genomics. 2008;8(1):69-78.

37. Palusa SG, Ali GS, Reddy AS. Alternative splicing of pre-mRNAs of Arabidopsis serine/arginine-rich proteins: regulation by hormones and stresses. Plant J. 2007:49(6):1091-107.

38. Mazzucotelli E, Mastrangelo AM, Crosatti C, Guerra D, Stanca AM, Cattivelli L. Abiotic stress response in plants: when post-transcriptional and posttranslational regulations control transcription. Plant Sci. 2008;174(4):420-31.

39. Maquat LE. Nonsense-mediated mRNA decay: splicing, translation and mRNP dynamics. Nat Rev Mol Cell Biol. 2004;5(2):89-99.

40. Hiller M, Huse K, Platzer M, Backofen R. Creation and disruption of protein features by alternative splicing-a novel mechanism to modulate function. Genome Biol. 2005;6(7):R58.

41. van Bentem SF, Vossen JH, Vermeer JE, de Vroomen MJ, Gadella TW, Haring MA, Cornelissen BJ. The subcellular localization of plant protein phosphatase 5 isoforms is determined by alternative splicing. Plant Physiol. 2003;133(2):702-12.

42. Terasawa K, Sato N. Visualization of plastid nucleoids in situ using the PEND-GFP fusion protein. Plant Cell Physiol. 2005;46(4):649-60.

43. Izaguirre-Mayoral M, Sinclair T. Soybean genotypic difference in growth, nutrient accumulation and ultrastructure in response to manganese and iron supply in solution culture. Ann Bot. 2005;96(1):149-58.

44. Thoiron S, Pascal N, BRIAT JF. Impact of iron deficiency and iron re-supply during the early stages of vegetative development in maize (Zea mays L.). Plant Cell Environ. 1997;20(8):1051-60.

45. Gan $\mathrm{S}$, Amasino RM. Inhibition of leaf senescence by autoregulated production of cytokinin. Science. 1995;270(5244):1986-8.

46. Weaver LM, Gan S, Quirino B, Amasino RM. A comparison of the expression patterns of several senescence-associated genes in response to stress and hormone treatment. Plant Mol Biol. 1998;37(3):455-69.

47. Foreman J, Demidchik V, Bothwell JH, Mylona P, Miedema H, Torres MA, Linstead P, Costa S, Brownlee C, Jones JD. Reactive oxygen species produced by NADPH oxidase regulate plant cell growth. Nature. 2003; 422(6930):442-6.

48. Garcia M, Myouga F, Takechi K, Sato H, Nabeshima K, Nagata N, Takio S, Shinozaki K, Takano H. An Arabidopsis homolog of the bacterial peptidoglycan synthesis enzyme MurE has an essential role in chloroplast development. Plant J. 2008;53(6):924-34.

49. Motohashi R, Nagata N, Ito T, Takahashi S, Hobo T, Yoshida S, Shinozaki K. An essential role of a TatC homologue of a $\Delta \mathrm{pH}$-dependent protein transporter in thylakoid membrane formation during chloroplast development in Arabidopsis thaliana. Proc Natl Acad Sci. 2001;98(18):10499-504.

50. Sumanta N, Haque Cl, Nishika J, Suprakash R. Spectrophotometric analysis of chlorophylls and carotenoids from commonly grown fern species by using various extracting solvents. Res J Chem Sci. 2014;4(9):63-9.
51. Beauchamp C, Fridovich I. Superoxide dismutase: improved assays and an assay applicable to acrylamide gels. Anal Biochem. 1971;44(1):276-87.

52. Hoffmann A, Hammes E, Plieth C, Desel C, Sattelmacher B, Hansen U-P. Effect of $\mathrm{CO} 2$ supply on formation of reactive oxygen species in Arabidopsis thaliana. Protoplasma. 2005;227(1):3-9.

\section{Publisher's Note}

Springer Nature remains neutral with regard to jurisdictional claims in published maps and institutional affiliations.
Ready to submit your research? Choose BMC and benefit from:

- fast, convenient online submission

- thorough peer review by experienced researchers in your field

- rapid publication on acceptance

- support for research data, including large and complex data types

- gold Open Access which fosters wider collaboration and increased citations

- maximum visibility for your research: over $100 \mathrm{M}$ website views per year

At BMC, research is always in progress.

Learn more biomedcentral.com/submissions 